\title{
BMJ Open Consent and widespread access to personal health information for the delivery of care: a large scale telephone survey of consumers' attitudes using vignettes in New Zealand
}

\author{
Dick Whiddett, ${ }^{1}$ Inga Hunter, ${ }^{1}$ Barry McDonald, ${ }^{2}$ Tony Norris, ${ }^{3}$ John Waldon ${ }^{4}$
}

To cite: Whiddett $D$, Hunter I, McDonald B, et al. Consent and widespread access to personal health information for the delivery of care: a large scale telephone survey of consumers' attitudes using vignettes in New Zealand. BMJ Open 2016;6:e011640. doi:10.1136/bmjopen-2016011640

- Prepublication history and additional material is available. To view please visit the journal (http://dx.doi.org/ 10.1136/bmjopen-2016011640).

Received 24 February 2016 Revised 6 July 2016 Accepted 1 August 2016

CrossMark

For numbered affiliations see end of article.

Correspondence to Dr Dick Whiddett; r.j.whiddett@massey.ac.nz

\section{ABSTRACT}

Objectives: In light of recent health policy, to examine factors which influence the public's willingness to consent to share their health information in a national electronic health record (EHR).

Design: Data were collected in a national telephone survey in 2008. Respondents were presented with vignettes that described situations in which their health information was shared and asked if they would consent to such sharing. The subset, consisting of the 18 vignettes that covered proving care, was reanalysed in depth using new statistical methods in 2016.

Setting: Adult population of New Zealand accessible by telephone landline.

Participants: 4209 adults aged 18+ years in the full data set, 2438 of which are included in the selected subset.

Main outcome measures: For each of 18 vignettes, we measured the percentage of respondents who would consent for their information to be shared for 2 groups; for those who did not consider that their records contained sensitive information, and for those who did or refused to say.

Results: Rates of consent ranged from $89 \%(95 \% \mathrm{Cl}$ $87 \%$ to $92 \%$ ) for sharing of information with hospital doctors and nurses to $51 \%$ (47\% to $55 \%$ ) for government agencies. Mixed-effects logistic regression was used to identify factors which had significant impact on consent. The role of the recipient and the level of detail influenced respondents' willingness to consent ( $p<0.0001$ for both factors). Of the individual characteristics, the biggest impact was that respondents whose records contain sensitive information (or who refused to answer) were less willing to consent $(p<0.0001)$.

Conclusions: A proportion of the population are reluctant to share their health information beyond doctors, nurses and paramedics, particularly when records contain sensitive information. These findings may have adverse implications for healthcare strategies based on widespread sharing of information. Further research is needed to understand and overcome peoples' ambivalence towards sharing their information.

\section{Strengths and limitations of this study}

- The study provides quantitative estimates of the extent to which health service consumers would consent to share their personal health information with various people in the delivery of care.

- The findings indicate the extent that the use of summary care records might increase consent for sharing information.

- The findings quantify the extent to which the presence of sensitive information reduces consumers' willingness to consent to share their information.

- The data used in this paper contain responses to 6584 vignettes, from 2438 respondents.

- A limitation of the study is that it is based on responses to theoretical scenarios rather than observed behaviour.

\section{INTRODUCTION}

On the 3 November 2015, the New Zealand health minister announced four new areas of future focus for information technology (IT) investment across the health system in New Zealand $^{1}$ that align with the National Health Strategy. ${ }^{2}$ The first priority area is

A single national electronic health record for New Zealanders that will provide information via patient and provider portals to enable clinicians, working in hospitals and in the community, to access important patient information in one place. ${ }^{1}$

This direction builds on the previous National Health IT Plan $^{3}$ which started in 2010 and is similar to that of many other countries, such as Australia ${ }^{4}$ and the $\mathrm{UK}^{5}$ whose public health services have a similar structure and use of IT. $^{6}$ The arguments put forward in these proposals are that improved 
access to information will enhance the ability to coordinate the delivery of care by a more diverse team of clinicians and allied healthcare professionals and will empower patients to become more engaged in their own care. These changes should lead to an overall improvement in the efficiency with which care can be provided and help to meet the ever-increasing demands being placed on the healthcare services.

The National Information Board, part of the UK National Health Service, in their strategy document Personalised health and care 2020: a framework for action, ${ }^{5}$ rightly recognises the importance of public trust in the systems:

Our success at putting information to work more effectively for patients and carers is dependent on sustaining the trust and confidence of the public in the collection, storage and use of their sensitive personal data. (p. 39)

Without trust patients may be unwilling to contribute information, which will undermine the benefits of information sharing, and some patients may even forego treatment in order to maintain their privacy. ${ }^{78}$ One of the proposals of the strategy is for wide ranging public consultation on the handing of such sensitive data (p. 41). A similar public consultation approach is being adopted in New Zealand with several design workshops in progress looking at the development of consumercentric electronic health record (EHR). ${ }^{9}$

A major challenge in the design of EHRs is that members of the public hold such diverse views of what is an appropriate use of their data that it is unlikely that an overall consensus will ever be achieved, and compromises will have to be made. However, to date there seems to have been no debate within the academic literature or the public domain as to what level of public consensus is appropriate before systems are implemented or their use mandated. A threshold of $80 \%$ is often used in medically related policy decisions, such as adherence to medication, ${ }^{10}$ performance assessment ${ }^{11}$ and human resource allocation for health outcomes, ${ }^{12}$ but the issue of the level of acceptance is not addressed in the policy documents.

This paper contributes to this arena by presenting additional results from a large scale investigation using vignettes into New Zealanders' attitudes towards the sharing of their personal health records.

Preliminary results of broad descriptive analysis of the first 1828 respondents have been reported elsewhere but identified that respondents were most willing (ie, would consent) to share their information for the purposes of providing clinical care but that this consent varied by recipient. ${ }^{13}$ In light of the move towards a single national EHR accessible by a diverse team of clinicians in New Zealand, the authors re-examined the full data set from 4209 respondents with new analysis methods previously unavailable. The aim was to identify factors that might influence this variation in consent to share personal health information for clinical care. These results are presented in this paper.

\section{METHODS}

The project used computer-automated telephone interviewing with vignettes to conduct a quantitative national survey of the attitudes of New Zealanders towards access to their personal health information. A more detailed description of the methodology used is reported elsewhere. $^{13}$

In summary, a series of vignettes were generated to capture how personal health information might be used, and respondents were asked about their attitude to, and whether they would consent to, such access. The advantage of directive responses in vignettes is that they provide the same contextual framework for all respondents, thus the data collected can be defined and standardised, leading to more uniform data and comparison of responses. $^{1415}$

The vignette framework was initially developed in the UK for the Patient Electronic Record, Information and Consent (PERIC) project, ${ }^{16}$ where each vignette contained various permutations of the four attributes contained in a generic vignette as follows:

$<$ person requesting information $>$ would like to access your medical notes which contain <content of medical information $>$ as $<$ reason for request $>$. The information about you would contain $<$ type of identification details $>$

The possible values for the attributes were tailored to the New Zealand context in a series of focus groups, and the comprehensibility of the vignettes when they were delivered via telephone interviews was tested in a pilot study.

A typical vignette was:

A doctor or practice nurse working in a GP setting would like access to your notes which contain all your medical history as part of the health care that you are receiving. The information about you would contain your name and address.

The wording in the questionnaire script for the telephone interviewers was extensively pilot tested. The interview script included instructions for the telephone interviewers to check at each scenario that the participant had understood the scenario and to explain any terms that the participant was unsure of.

Each respondent was asked to respond to a series of vignettes, the median number of vignettes per interview was 7 , but interviewers and respondents were given some discretion over when to stop, so the number of responses ranged between 1 and 19 vignettes per respondent.

In this paper, we focus only on the subset of vignettes where <reason for request> is the 'provision of care' (the other four secondary purposes, which are not discussed here, were 'quality audit', 'financial audit', 
'improving the health of New Zealanders' and 'assessing eligibility for financial assistance'). This limits the range of $<$ person requesting information $>$ to nine types of care providers and administrators. It also limits the <type of identification> to 'name and address' for all recipients; the use of anonymised or semianonymised data was not considered in the provision of care.

An alternative to providing access to complete medical records stored within an EHR is to provide access to a summary of health events. ${ }^{17}$ Thus, in this paper, we focus on vignettes where <content of medical information> is either 'full medical history' (explained as 'all your past history') or 'brief summary' (explained as 'a brief summary of your medical notes rather than the complete details'). Based on previous research, ${ }^{18}$ we postulated that respondents would be more willing to consent to sharing a brief summary of their history (analogous to a summary care record ${ }^{19}$ ) rather than their full history.

Thus, the results for 18 out of the full set of 87 vignettes are considered in this paper; the majority of respondents answered 2 of these 18 vignettes within their full set of responses, with $95 \%$ of respondents answering 4 or less of these 18 vignettes (their remaining vignette answers being out of scope for this paper).

For each vignette, the interviewer read the vignette and then asked about how the respondent would feel about the situation. The first question asked for a response on a Likert scale in the form 'On a scale of 110 , where 1 is very uncomfortable and 10 is very comfortable, how comfortable would you be for this person to see your medical notes?'

It is possible for respondents to feel uncomfortable about the situation but still agree for it to occur. Therefore, a second fixed choice question asked if the respondent would consent for the information sharing in the vignette to happen anyway, with the options of yes/no. Owing to limitations of space, this paper will focus on whether people would actually accept systems, and so we present the results of the fixed choice question and report the percentage of respondents who would consent to sharing their information for a particular vignette where the $<$ reason for request $>$ is the 'provision of care'.

At the beginning of each interview, the respondent was asked to give their gender, age and ethnicity (for comparison with national demographics). After the final vignette, the interviewer asked the respondent if they have a chronic condition. The authors postulated that having a chronic condition resulted in more contact and thus more familiarity with the health sector, and a greater understanding of the value of sharing their health information hence would be more willing to consent to share their health information.

Finally respondents were asked if they had any information within their record which they would consider to be sensitive, as we postulated that this would make them less likely to consent to share their information due to privacy concerns. ${ }^{20}$ They were not asked what that information might be.

\section{Sample}

Respondents were obtained by random calling of a New Zealand-wide sample of telecom residential numbers during the evenings in the first half of 2008; 'no replies' were called back three times and people who were too busy were offered a call at a different time to reduce non-respondent bias. Consent was given verbally at the beginning of the interviews, all stored data were totally anonymous. Interviews were held with people aged 18+ years, with no stratification within the sample. The respondents should therefore be reasonably representative of the general population and of the users of primary care services, although there may be some under-representation of lower socioeconomic households who do not have a landline telephone.

At the time of the survey, the New Zealand population was $\sim 3138000$ people aged 18 years and over. ${ }^{21}$ For each vignette, a sample of about 384 responses was required to estimate a proportion within a $5 \%$ margin of error with $95 \%$ confidence. The full data set from the survey included responses to 31146 vignettes from 4209 respondents; the subset of the data used in this paper contains responses to 6584 vignettes, from 2438 respondents, giving an average of 366 responses per vignette.

\section{Patient involvement}

No patients were involved in setting the research question or the outcome measures. Lay people were involved in the development and pilot testing of the interview schedule and of the use of vignettes within telephone interviews. There are no plans to involve patients in dissemination. The participants are thanked in the acknowledgments.

\section{Analysis}

The nlme package in $\mathrm{R}$ was used for inferential analysis. The binary response was modelled using logistic regression to identify which factors had a significant impact on the likelihood of agreement. The nlme package uses a mixed-effects logistic model to adjust for the correlation between answers to multiple scenarios by the same respondent. The detailed output of the logistic regression analysis is provided in online supplementary appendix 1. For visualisation purposes, some descriptive statistics are shown using Minitab V.17 output.

The amount of missing data from the demographic data was very small and deemed unlikely to materially affect the results, and so were treated as missing at random (row was dropped whenever the variable was included in the analysis). There were no missing data for the responses to the vignettes. 


\section{RESULTS}

\section{Respondents}

Table 1, below, provides a summary of the various characteristics of the respondents, and where possible, it also provides a corresponding breakdown of the New Zealand population. $^{22}$ Table 1 also provides the overall rate of consent for each category and the significance level of each characteristic obtained by the modelling.

The results show that females and ethnic Europeans were over-represented in the sample. However, the modelling suggests that gender and ethnicity do not have a significant impact on people's willingness to share their information, so we do not believe that this imbalance has influenced the results. Middle-aged people were also over-represented in the sample. Age was found to be a significant factor for consent $(\mathrm{p}=0.017)$, with the middle-aged group being less willing to consent than the young or elderly.

We had postulated that respondents who had chronic conditions would be more aware of the benefits of sharing their information and would therefore be more willing to consent to sharing. The results support this hypothesis and show that people with chronic conditions tend to be more willing to share their information $(\mathrm{p}=0.022)$.

Of all the characteristics of the respondents, the presence of sensitive information had the most significant impact on their rate of consent and thus support our second hypothesis. While most respondents said their records did not contain sensitive information, $19.5 \%$ said that they did and $1.5 \%$ refused to answer the question; responses of the latter two groups were statistically different from those without sensitive information $(\mathrm{p}<0.0001$, $\mathrm{p}=0.0004)$, but not from each other $(\mathrm{p}=0.057)$.

\section{Responses to vignettes}

The percentages of respondents who would consent to sharing information for different vignettes are presented in figures 1 and 2 below. Owing to the statistically significant impact that the presence of sensitive information has on peoples' willingness to share information, we have separated the respondents into two groups: figure 1 presents the results for respondents who did not have sensitive information; figure 2 presents the combined results for the respondents who did have sensitive information or who refused to say. The data in the figures are ordered first by the role of the recipient of the information, and then by the level of detail.

The figures illustrate the wide range in the acceptability of sharing information for the various vignettes, from over $90 \%$ consenting to sharing information with hospital doctors to $49 \%$ consenting to sharing with government agencies. Overall, respondents consented to share information in response to only $68 \%$ of the vignettes and would not consent to the remaining $32 \%$.

\section{Role of recipient}

The role of the recipient had the biggest impact on the likelihood of consent to share information $(p<0.001$, see online supplementary appendix 1). Respondents were much more willing to share information with doctors or nurses in hospitals or general practitioner (GP) practices or with ambulance paramedics than with other healthcare workers or administrators (see figures 1 and 2 below). Results for the allied health professionals, who fell in the middle of the range of agreement, were statistically significantly different from the results for all of the other roles (see online supplementary appendix 1). However, it was not the case that responses for all roles differed from all other roles; for example, there was no significant difference between the responses for hospital doctors and ambulance paramedics.

\section{Presence of sensitive information}

Having sensitive information, or refusing to say, both lowered the probability of consent to share information compared with not having sensitive information $(\mathrm{p}=0.037, \mathrm{p}=0.037$, online supplementary appendix 1$)$. For simplicity, figures 1 and 2 illustrate the effect using the raw data rather than the nlme model. Figure 1 illustrates that over $80 \%$ of people without sensitive information would consent to share their information with all doctors, nurses or ambulance paramedics, but they are much less likely to consent to share with other healthcare professionals or administrators. Figure 2 shows how the likelihood of consent falls for all professional groups when the sensitive information is present (or the person refuses to say); even GPs fail to reach the $80 \%$ level of consent with only $76 \%$ consenting. Some groups suffer even bigger falls in levels of consent; for example, the level of consent to share information with allied health professionals and laboratory staff both fall by over $20 \%$ for respondents with sensitive information or refusing to say.

\section{Level of detail}

Two levels of detail of information were used within the vignettes. The 'full medical history' was the least preferred option and was statistically different from the 'brief summary' $(\mathrm{p}<0.001$, see online supplementary appendix 1). The average level of consent for the 'full medical history' was $4.6 \%$ below that of the 'brief summary' and up to $8.1 \%$ lower in some vignettes.

\section{DISCUSSION/CONCLUSIONS}

In $32 \%$ of their answers, respondents indicated that they would be unwilling to share their information in the way that was proposed to them; the results suggest that many of the information-sharing scenarios proposed under the new government strategies are unlikely to reach the, somewhat arbitrary, $80 \%$ level of consent from the public. The potential unwillingness of people to share information severely undermines the credibility of a strategy based on open information sharing and needs to be addressed. 
Table 1 Characteristics of respondents

\begin{tabular}{|c|c|c|c|c|c|c|}
\hline Characteristic & Categories & $\begin{array}{l}\mathbf{N} \text { in } \\
\text { sample }\end{array}$ & $\begin{array}{l}\text { Per cent } \\
\text { in sample }\end{array}$ & $\begin{array}{l}\text { Per cent } \\
\text { in NZ } \\
\text { population }\end{array}$ & $\begin{array}{l}\text { Per cent of } \\
\text { sample consenting to } \\
\text { share information }\end{array}$ & $\begin{array}{l}\text { Significance } \\
\text { of factor }\end{array}$ \\
\hline \multirow[t]{2}{*}{ Gender } & Male & 763 & 31.3 & 49 & 68.5 & 0.640 \\
\hline & Female & 1675 & 68.7 & 51 & 67.5 & \\
\hline \multirow[t]{3}{*}{ Ethnicity } & European & 2040 & 83.7 & 74 & 67 & 0.509 \\
\hline & Maori & 238 & 9.8 & 15 & 69.5 & \\
\hline & Asian/other & 160 & 6.6 & 12 & 67.2 & \\
\hline \multirow[t]{3}{*}{ Age } & $18-34$ & 397 & 16.3 & 29 & 70.1 & 0.017 \\
\hline & $35-64$ & 1404 & 57.6 & 52 & 65.6 & \\
\hline & $65+$ & 637 & 26.1 & 19 & 71.2 & \\
\hline \multirow[t]{2}{*}{ Chronic } & Yes & 592 & 24.4 & NA & 71.5 & 0.022 \\
\hline & No & 1846 & 75.6 & NA & 66.6 & \\
\hline Sensitive & No & 1930 & 79.2 & NA & 70.6 & 0.00005 \\
\hline \multirow[t]{2}{*}{ information } & Yes & 472 & 19.4 & NA & 63.9 & \\
\hline & Refused & 36 & 1.5 & NA & 49.4 & \\
\hline
\end{tabular}

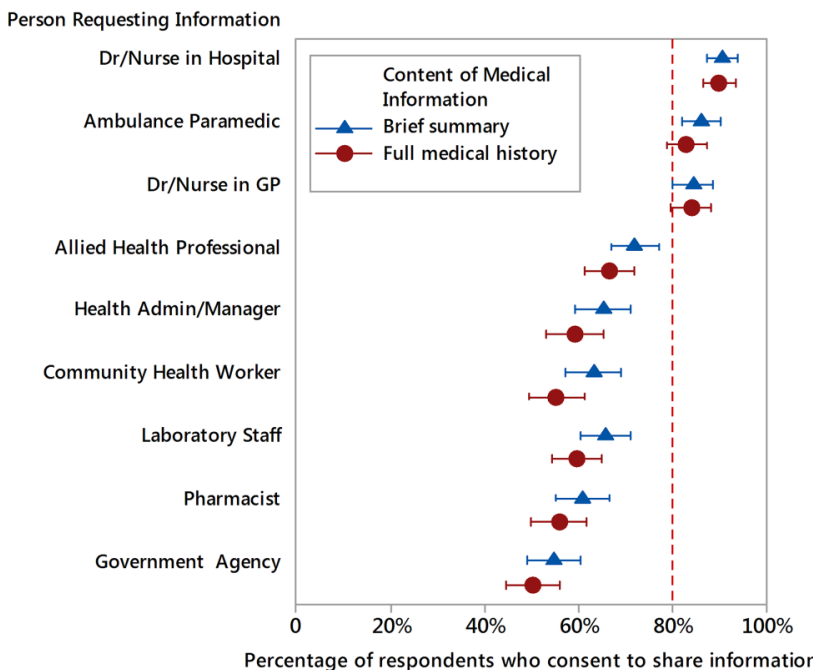

Figure 1 Interval plot depicting mean percentage (and 95\% $\mathrm{Cl}$ ) of respondents without sensitive information consenting to share information by <person requesting information $>$ and $<$ content of medical information>. GP, general practitioner.

The findings align with previous localised or qualitative studies in the UK ${ }^{162324}$ and New Zealand ${ }^{18}$ which have indicated that people are often reluctant to consent to sharing their personal health information; some people are even reluctant to share information with their GP. We confirm previous findings ${ }^{18}$ that the role of the recipient of the information has a major impact on the acceptability of information sharing; the vast majority of people would consent to sharing information with doctors, nurses and ambulance paramedics; however, they are significantly less willing to share information with other healthcare professionals and administrators. As in previous research, restricting the amount of information to be shared to a brief summary increased the level of consent. ${ }^{18}$ Of the individual characteristics investigated, most had little effect on peoples willingness to consent to sharing; however, as

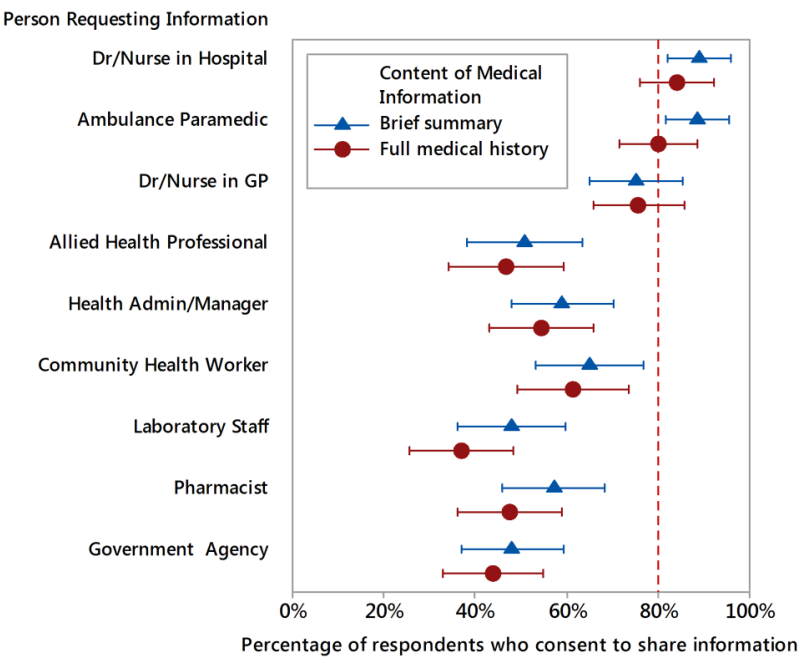

Figure 2 Interval plot depicting mean percentage (and 95\% $\mathrm{Cl}$ ) of respondents with sensitive information (or refusing to say) consenting to share information by $<$ person requesting information $>$ and $<$ content of medical information $>$. GP, general practitioner.

with previous studies, ${ }^{18}{ }^{25}$ having sensitive information in the record significantly reduced respondents willingness to share.

The study canvassed the opinions and attitudes of a very large and diverse sample of the New Zealand population and the findings should be representative of the overall population. New Zealand has been at the forefront of using electronic medical records, ${ }^{26}$ with $100 \%$ of GP practices now using such systems, ${ }^{2}$ so respondents would be familiar with their medical records being in an electronic format and with their health information being shared electronically, for example, for referrals, prescriptions and investigations. The systematic use of vignettes to frame our questions helped respondents to understand the questions and enhanced the consistency of their responses. Furthermore, the interviewers were provided with additional information to clarify 
respondents' questions about vignettes; however, there remains the possibility that some respondents did not fully understand the implications of some vignettes or that they might respond differently in practice.

A limitation of the study is that it related to the context and population of New Zealand. However, the vast majority of respondents identified with a European ethnicity and we did not find that ethnicity had any significant influence in the results of our survey, so the findings may be applicable in similar contexts and populations, such as in Australia and the UK. However, care should be taken in extrapolating the findings to different contexts or more diverse populations. Although there was an overrepresentation of females in our respondents, we do not believe this influenced the pattern of results as there was no indication that gender influenced respondents' attitudes. Some of the subgroups of respondents (such as those with sensitive information) are relatively small compared with the overall data set (hence the wide error bars in figure 2), so the conclusions drawn from this data need to be treated with some caution. Furthermore, given the age of the study and the rate of change of technology acceptance in society, it is possible that the levels of acceptance have since changed and additional collection of current attitudes would be useful and would also provide a longitudinal perspective.

Considering these results, we suggest two techniques which could be considered for the design and implementation of future health information systems which may result in more people consenting to share their health information with the wide range of healthcare professional who are involved in providing care. These techniques are given below.

\section{Summary care records}

In virtually all situations, limiting access to just a brief summary record rather than a full medical history resulted in an increase in consent. Typically, limiting content resulted in about $5 \%$ more respondents indicating that they would consent to share their information, with the size of the increase being bigger for the more contentious vignettes.

Within New Zealand, there have been a number of local initiatives using 'opt-off' consent to introduce summary records which have been reasonably successful, ${ }^{27}$ thus the concept of using brief summary records has been shown to be acceptable in New Zealand. The more problematic experience elsewhere (see, eg, the UK Summary Care Record ${ }^{28}$ and the Australian Personally Controlled Electronic Health Record (PCEHR), now called the My Health Record ${ }^{29}$ ) used an 'opt-in' consent strategy which may explain this difference in experience.

\section{Managing sensitive information}

Having sensitive information reduces the acceptability of sharing information with GPs and has a dramatic effect on the acceptability of sharing information with allied health professionals, where $\sim 49 \%$ of respondents with sensitive information indicated that they would consent to sharing, compared with $69 \%$ of those without sensitive information.

We suggest that co-designing with consumer ways to address the management of sensitive information within EHRs might increase consent for sharing information. If sensitive information could be managed so that it ceased to be considered sensitive (eg, by reducing stigma attached to certain health information ${ }^{30}$ ), or so that consumers have control over that information and how it is accessed or shared (eg, by withholding some information or providing only selective access by certain recipients, etc), then the rates of acceptance of information sharing might increase to a level comparable to people without sensitive information. Using allied health professionals as an example, since about one in five people had sensitive information (20\%), this might translate into a $\sim 5 \%$ increase in the number of people willing to consent to share health information overall.

The findings suggest that the use of both of these techniques might each result in a $5 \%$ increase in the number of respondents consenting. When translated into number of individuals within a country's population, the practical relevance of a 5\% increase assumes a larger pragmatic significance. Given that the New Zealand population was $\sim 3138000$ people aged 18 years and over, ${ }^{21}$ a $5 \%$ increase in consent could amount to 156900 individuals. For the UK and Australia and other larger population countries, this increase would be correspondingly larger.

Given the potential improvement in acceptability, we suggest that further research is required to examine whether it is possible to identify features that might encourage people with sensitive information to share their information more widely. However, it might be found that giving people more control over who can access their information will result in less information being shared overall. Note that we did not define what constituted sensitive information, it was left to the respondents to determine what they thought was sensitive; it would therefore be useful to conduct further research to identify the kinds of information which are considered sensitive and the extent to which people would opt-out of sharing information.

Our research highlights the variability in the public's attitudes towards sharing their health information with different healthcare professionals. In this paper, we have emphasised some of the findings which suggest some techniques that could be designed into EHR systems which might increase the acceptance of information sharing. This issue will become increasingly important as health services expand the role played by various allied healthcare professionals and pharmacists. Further research is needed to gain a better understanding of the underlying causes of the difference in the public's attitudes towards different professional groups in order to address this imbalance.

Finally, our results highlight the diversity of public opinion and the difficulty of gaining total consensus on 
the use of health information; we hope that this paper will spark some debate about what level of consensus is appropriate before EHR systems are implemented and about how to meet the needs of the remaining minority who are unwilling to share their information. In addition, there needs to be more policy discussions about what level of investment is justified to produce the conditions which may extend the proportion of consumers consenting to share their records. For example, if an $80 \%$ consensus level is adopted, how could this best be achieved, what is the investment needed, would that investment be justified and what criteria would be used to determine that justification?

\section{Author affiliations}

${ }^{1}$ School of Management, College of Business, Massey University, Palmerston North, New Zealand

${ }^{2}$ Institute of Natural and Mathematical Sciences, Massey University, Auckland, New Zealand

${ }^{3}$ School of Engineering and Advanced Technology, Massey University, Auckland, New Zealand

${ }^{4}$ Faculty of Medicine, Muru Marri Indigenous Health Unit, School of Public Health \& Community Medicine, University of New South Wales, Sydney, New South Wales, Australia

Acknowledgements The authors would like to acknowledge the many respondents who generously gave their time to answer our questions, the team at the Survey Research Unit, University of Auckland for their professional execution of the survey and the many groups and individuals who contributed to the development of the questionnaire and vignettes.

Contributors DW, IH, TN and JW initiated the study, contributed to its design, obtained funding and ethical approval and managed the project implementation. BM undertook the data analysis, statistical analysis and advised on the interpretation. All authors interpreted data, reviewed successive drafts and approved the final version of the article.

Funding This project was supported by the Health Research Council of New Zealand-Contract 07/215R.

Competing interests None declared.

Ethics approval The project was approved by the Massey University Human Research Ethics Committee WGTN Application 05/67.

Provenance and peer review Not commissioned; externally peer reviewed.

Data sharing statement No additional data are available.

Open Access This is an Open Access article distributed in accordance with the Creative Commons Attribution Non Commercial (CC BY-NC 4.0) license, which permits others to distribute, remix, adapt, build upon this work noncommercially, and license their derivative works on different terms, provided the original work is properly cited and the use is non-commercial. See: http:// creativecommons.org/licenses/by-nc/4.0/

\section{REFERENCES}

1. Minister of Health. Next phase of the Health IT Programme announced. 03 November 2015. http://healthitboard.health.govt.nz/ health-it-programme-2015-2020-0/next-phase-health-it-programmeannounced

2. Minister of Health. New Zealand Health Strategy: future direction. Wellington: Ministry of Health, 2016. ISBN: 978-0-947491-87-1. http://www.health.govt.nz/system/files/documents/publications/ new-zealand-health-strategy-future-direction-apr16_1.pdf

3. Minister of Health. National Health IT Plan Update for 2013/14. Wellington: Ministry of Health, 2013. ISBN: 978-0-478-41555-1. http://healthitboard.health.govt.nz/our-programmes/national-healthit-plan

4. Australian Health Ministers' Conference. National E-Health Strategy. 2008 https://www.health.gov.au/internet/main/publishing.nsf/Content/
69B9E01747B836DCCA257BF0001DC5CC/\$File/Summary\% 20National\%20E-Health\%20Strategy\%20final.pdf

5. National Information Board and Department of Health. Personalised Health and Care 2020: a framework for action. 2014. https://www. gov.uk/government/uploads/system/uploads/attachment_data/file/ 384650/NIB_Report.pdf

6. Mossialos E, Wenzl M, Osborn R, Sarnak D, eds. International profiles of health care systems, 2015. The Commonwealth Fund, 2016. http:// www.commonwealthfund.org/ /media/files/publications/fund-report/ 2016/jan/1857 mossialos intl_profiles 2015 v7.pdf?la=en

7. Sankar P, Mora S, Merz JF, et al. Patient perspectives of medical confidentiality. J Gen Intern Med 2003;18:659-69.

8. Hunter I, Ede GH, Whiddett R. Increased electronic information sharing by sexual health services: confidentiality and consent. Health Informatics J 2014;20:3-12.

9. Minister of Health. Design workshop progresses on consumercentric EHR. 05 April 2016. http://healthitboard.health.govt.nz/ health-it-programme-2015-2020-0/design-workshop-progressesconsumer-centric-ehr

10. Ho PM, Bryson CL, Rumsfeld JS. Medication adherence its importance in cardiovascular outcomes. Circulation 2009:119:3028-35.

11. Bauer JC. Paradox and imperatives in health care: redirecting reform for efficiency and effectiveness. CRC Press, 2014.

12. Speybroeck N, Kinfu Y, Dal Poz MR, et al. Reassessing the relationship between human resources for health, intervention coverage and health outcomes. World Health Organization, 2006. http://www.who.int/hrh/documents/reassessing_relationship.pdf

13. Hunter IM, Whiddett RJ, Norris AC, et al. New Zealanders' attitudes towards access to their electronic health records: preliminary results from a national study using vignettes. Health Informatics J 2009;15:212-28.

14. Poulou M. The role of vignettes in the research of emotional and behavioural difficulties. Emotional Behav Difficulties 2001;6:50-62.

15. Evans SC, Roberts MC, Keeley JW, et al. Vignette methodologies for studying clinicians' decision-making: validity, utility, and application in ICD-11 field studies. Int J Clin Health Psychol 2015;15:160-70.

16. Shickle D, Carlisle J, Wallace S, et al. Patient Electronic Record, Information and Consent (PERIC): public attitudes to protection and use of personal health information. ScHARR Report Series 7, School of Health and Related Research, University of Sheffield, 2002.

17. Health Information Strategy Steering Committee. Health Information Strategy for New Zealand. Wellington: Ministry of Health, 2005.

18. Whiddett R, Hunter I, Engelbrecht J, et al. Patients' attitudes towards sharing their health information. Int J Med Inform 2006;75:530-41.

19. NHS Connecting for Health. Connecting for health business plan. London: Department of Health, 2004. http://www.connectingforhealth. nhs.uk

20. Sankar P, Jones NL. To tell or not to tell: primary care patients disclosure deliberations. Arch Intern Med 2005;165:2378-83.

21. Elections New Zealand. Enrolment Statistics (cited 31 July 2008) http://www.elections.org.nz/research-statistics/enrolment-statisticselectorate

22. Statistics New Zealand. 2013 Census. http://www.stats.govt.nz/ Census/2013-census/data-tables/total-by-topic.aspx

23. NHS Information Authority. Share with care! People's views on consent and confidentiality of patient information. London: Department of Health, 2002. http://webarchive.nationalarchives.gov.uk 20130502102046/http://www.connectingforhealth.nhs.uk/resources/ archive/share_with_care.pdf (accessed online August 2016).

24. Riordan F, Papoutsi C, Reed JE, et al. Patient and public attitudes towards informed consent models and levels of awareness of electronic health records in the UK. Int J Med Inform 2015;84:237-47.

25. Powell J, Fitton R, Fitton C. Sharing electronic health records: the patient view. J Innov Health Inform 2006;14:55-7.

26. Pollock M. Better Information for better care-New Zealand's approach to efficient and affordable health care, White paper. New Zealand Trade and Enterprise (NZTE), April 2012. https://www.nzte. govt.nz/media/553044/final_nzte_europe_whitepaper_low.pdf

27. Bowden T, Coiera E. Comparing New Zealand's 'Middle Out' health information technology strategy with other OECD nations. Int $J$ Med Inform 2013;82:e87-95.

28. Greenhalgh T, Stramer K, Bratan T, et al. Adoption and nonadoption of a shared electronic summary record in England: a mixed-method case study. BMJ 2010;340:c3111.

29. Murphy J. The Hon Sussan Ley MP. Minister for Health. Patients to get new myHealth Record: \$485 'rescue' package to reboot Labor's e-Health failures. 10 May 2015. https://www.health.gov.au/internet/ ministers/publishing.nsf/Content/health-mediarel-yr2015-ley050.htm

30. Dixon-Woods M, Stokes T, Young B, et al. Choosing and using services for sexual health: a qualitative study of women's views. Sex Transm Infect 2001;77:335-9. 